\title{
Genome Analysis System for Actinomycetes: Development and Application
}

\author{
Jun Ishikawa \\ Department of Bioactive Molecules, National Institute of Infectious Diseases, \\ 1-23-1, Toyama, Shinjuku, Tokyo 162-8640, Japan \\ (Received Oct. 30, 2008 / Accepted Oct. 30, 2008 / Published Dec. 25, 2008)
}

In 1986, I moved from Prof. Y. Koyama's laboratory (Toho University) to Dr. K. Hotta's laboratory (National Institute of Health), and began a study on the cryptic kanamycin resistance gene of a streptomycin-producing Streptomyces griseus. It was not long before I cloned a 1.8-kb DNA fragment containing the kan gene encoding an aminoglycoside 3- $N$-acetyltransferase (AAC(3); Hotta et al., 1988; Ishikawa et al., 1988). Subsequently, I determined its nucleotide sequence to specify the coding region (Ishikawa \& Hotta, 1991). Initially, it was believed that obtaining the nucleotide sequence would allow identification of the gene interest. Unexpectedly, however, the coding region of the kan gene could not be readily specified because the $1.8-\mathrm{kb}$ sequence contained many candidate start and stop codons as well as open reading frames. However, the coding region of the kan gene was predicted quite easily by FRAME analysis (Bibb et al., 1984), a gene prediction method based on the distribution of third-letter $\mathrm{G}+\mathrm{C}$ content of each codon in high $\mathrm{G}+\mathrm{C}$ content bacteria. This experience led me to the computational analysis of sequence information, which has recently been called "bioinformatics".

When FRAME analysis was developed by Bibb et al., the software was implemented on only a few platforms such as the VAX systems. Therefore, I developed the FramePlot program from scratch in a BASIC language and distributed it to my colleagues. After several years, I re-implemented the FramePlot program as a web-based program with the invention of the World Wide Web in the mid-1990s. The graphical user interface and integration of the NCBI BLAST search made the FramePlot program an essential tool to analyze actinomycete genes because of its platform independence and ease of use (Fig. 1).

In 2000, Prof. Haruo Ikeda (Kitasato University) began the genome sequencing of $S$. avermitilis, an industrial microorganism producing avermectin. I agreed to help in sequence assembly and annotation of the genome sequence, because it was exciting work to unveil the longest bacterial genome sequence at that time. First, I modified the FramePlot program so that the program could handle genome-scale sequence data. In addition, I had to develop a great many shell- and Perl-scripts to handle hundreds of thousands of sequence traces, database search results, etc. This was very arduous work but a good opportunity to relearn computer programming. After one year, we over- came many difficulties and obtained a genome sequence as five supercontigs. Since this sequence was estimated to cover more than $99 \%$ of the genome, we could deduce the ability of this organism to produce secondary metabolites (Omura et al., 2001). Surprisingly, the S. avermitilis genome was found to have 25 secondary metabolite gene clusters, only a few of which were known before the determination of the genome sequence. On December 27, 2001, we finally completed the genome sequence. The final gap contained an 18 G-run (Fig. 2). The completion of the genome sequence yielded the discovery of five additional gene clusters (Ikeda et al., 2003), which could not have been identified before completion of the genome sequence due to the loss of gene context. Currently, 32 secondary metabolite gene clusters have been recognized by the continuous efforts of Prof. Ikeda's group. Furthermore, the relationships between genes and metabolites have been demonstrated experimentally for some of these clusters.

Thus, I established a genome analysis system, especially for high-G+C bacterial genomes. After sequencing of the S. avermitilis genome, I worked on genome sequencing projects of Mycoplasma penetrans (Sasaki et al., 2002), Symbiobacterium thermophilum (Ueda et al., 2004), Nocardia farcinica (Ishikawa et al., 2004), and S. griseus (Ohnishi et al., 2008). At present, six genome sequencing projects, including Kitasatospora setae and Actinoplanes

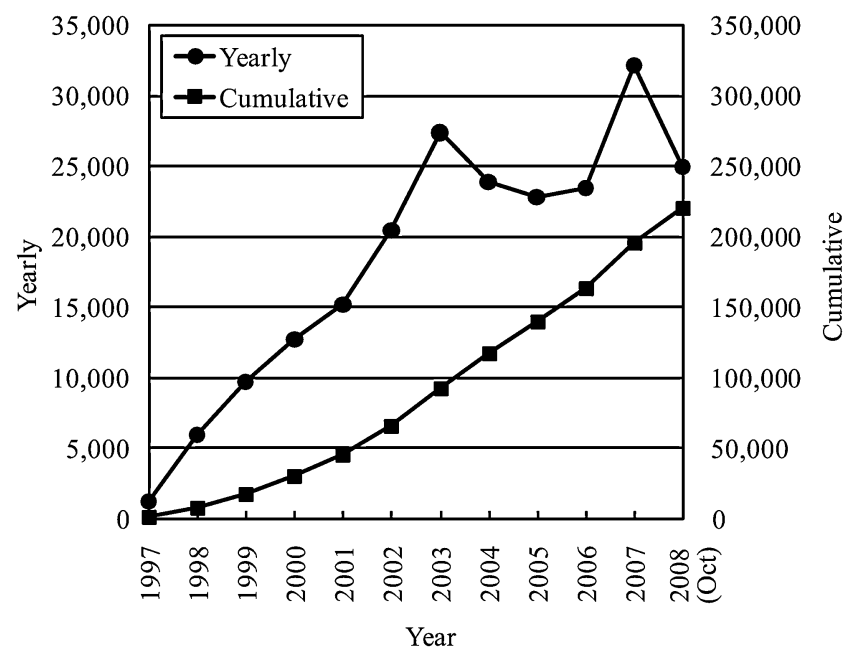

Fig. 1. Usage statistics of FramePlot. 


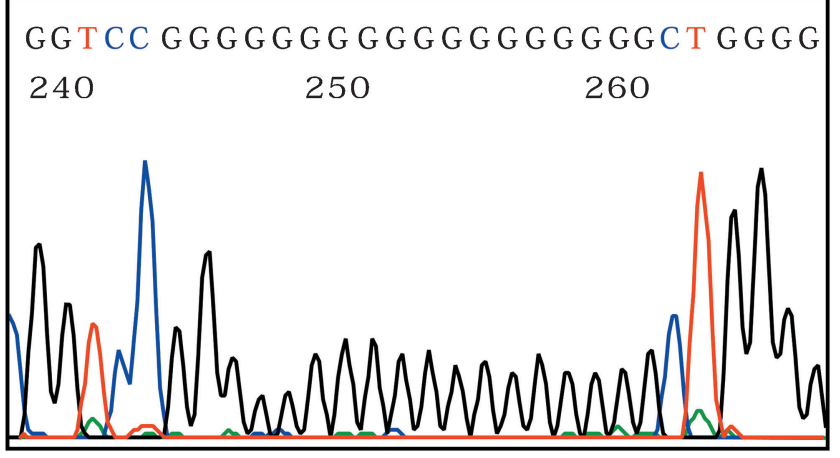

Fig. 2. Nucleotide sequence contained in the final gap of the $S$. avermitilis genome sequence assembly. The sequence was determined by transcriptional sequencing (Sasaki et al., 1998).

missouriensis, are using my system.

Completion of the genome sequence is not the final goal of my work, and of course the genome sequence must be used for post-genome sequence studies. Recently, I collaborated with Prof. Tohru Dairi's group (Toyama Prefectural University) in the discovery of a novel biosynthetic pathway for menaquinone (Hiratsuka et al., 2008). He performed detailed comparisons of published genome sequences and found that some bacteria, such as Streptomyces coelicolor A3(2), Helicobacter pylori and Campylobacter jejuni, lack genes for the known menaquinone biosynthetic pathway, although they synthesize this essential compound for their life. Prof. Dairi requested me a fantastic demand: "Can you specify which genes are responsible for menaquinone biosynthesis in the S. coelicolor A3(2) genome?". This request perplexed me but I soon had an idea. I considered that genes for a novel pathway could be specified by comparing orthologous genes between bacterial genomes having and lacking the known pathway, because menaquinone biosynthetic genes are essential for the bacteria. I confirmed my strategy by repeated simulations and finally narrowed down the likely candidates to 50 of 7,500 genes. Subsequently, Prof. Dairi's group demonstrated successfully that at least four hypothetical genes of $S$. coelicolor A3(2) were involved in the novel pathway. The work was commented to be "a tour de force" (Drahl, 2008).

The post-genome sequence analysis of $N$. farcinica accounts for the majority of my present work, which are aimed at understanding its characteristics such as pathogenicity, drug resistance, secondary metabolism and conversion of chemicals. At present, the most remarkable result from this work is probably the discovery of the duplication of RNA polymerase $\beta$ subunit gene (Ishikawa et al., 2006). We demonstrated the presence of two different RNA polymerase $\beta$ subunit genes, $r р о B$ and rpoB2, in the $N$. farcinica IFM 10152 genome. These two genes show $88 \%$ identity and $94 \%$ similarity at the deduced amino acid level. Moreover, comparison of their amino acid sequences with those of other bacterial RpoB proteins suggested that the nocardial RpoB protein is likely to be sensitive to rifampin, whereas RpoB2 protein contains substitutions at the rifampin-binding region likely to confer rifampin resistance. The introduction of rpoB2 conferred rifampin resistance to $N$. asteroides IFM 0319, which has neither rifampin resistance nor $r р о B$ duplication. Furthermore, unmarked rpoB2 deletion mutants of $N$. farcinica IFM 10152 showed no significant resistance to RIF (Table 1). These results indicated that rpoB2 was responsible for rifampin resistance in $N$. farcinica IFM 10152. We also demonstrated that $r p o B$ duplication was widespread in Nocardia species and correlated with the rifampin-resistant phenotype (Table 1). In addition to rpoB2, the $N$. farcinica genome contains many candidate genes for drug resistance, such as aminoglycoside phosphotransferase, $\beta$-lactamase,

Table 1. rроB duplication and rifampin resistance in Nocardia.

\begin{tabular}{|c|c|c|}
\hline Species, strain/plasmid & rpoB duplication* & Resistance $(\mu \mathrm{g} / \mathrm{ml})^{* *}$ \\
\hline N. farcinica IFM 10152 & + & $>100$ \\
\hline N. farcinica IFM $10152 \Delta r p o B 2$ & - & $<5$ \\
\hline N. farcinica IFM $10152 \Delta$ rpoB2/pNVrpoB2 & - & $>100$ \\
\hline N. farcinica IFM $0284^{\mathrm{T}}$ & + & $>100$ \\
\hline N. farcinica IFM 10125 & + & $>100$ \\
\hline N. asteroides IFM $0319^{\mathrm{T}}$ & - & $<5$ \\
\hline N. asteroides IFM $0319^{\mathrm{T}} / \mathrm{pNV} r p o B 2$ & - & $>100$ \\
\hline N. asteroides IFM 10159 & + & 25 \\
\hline N. asteroides IFM 10162 & - & $<5$ \\
\hline N. brasiliensis IFM $0236^{\mathrm{T}}$ & + & 50 \\
\hline N. brasiliensis IFM 1032 & + & $>100$ \\
\hline N. brasiliensis IFM 10160 & + & 50 \\
\hline N. terpenica IFM 0406 & + & $<5$ \\
\hline
\end{tabular}

*Estimated by Southern hybridization experiments.

** Determined after incubation at $37^{\circ} \mathrm{C}$ for $48 \mathrm{~h}$ on BHI agar plates containing various concentrations of rifampin. 
drug efflux pump, and ribosomal RNA methyltransferase genes. These candidate genes could explain almost all drug resistance profiles of $N$. farcinica. We will experimentally demonstrate not only their roles but also all the resistance genes of the genome (resistome) in future studies.

As part of the post-genome sequence study, we have developed genetic tools for Nocardia (Chiba et al., 2007) and have first succeeded in gene knockout (Ishikawa et al., 2006) in this microorganism. To facilitate studies on Nocardia, we have distributed our tools and techniques as well as the genome resources of $N$. farcinica. To date, we have provided $\mathrm{pNV}$ vectors to 18 researchers or research groups and 35 genomic DNA clones from the ordered plasmid library of the $N$. farcinica genome. Two reports have been published using our resources. Agematu et al. (2006) reported that $\mathrm{Nfa} 33880$ and $\mathrm{Nfa53110}$ are able to hydroxylate the $16 \alpha$ - or 17-position of testosterone, respectively. More recently, Martins et al. reported that nfal 8420 gene encodes an arylamine $N$-acetyltransferase and discussed its putative role in isoniazid resistance (Martins et al., 2008). I hope that our resources will continue to facilitate further valuable works.

Nocardia species have many important, interesting and valuable features. However, since the post-genome sequence analysis of $N$. farcinica has just begun, we do not have sufficient results to present here yet. However, the result of several on-going studies will be published elsewhere in the near future.

One of the most important subjects of actinomycetes genome analysis is the understanding of secondary metabolism. Although there have been a number of efforts to discover new secondary metabolites, it seems that most secondary metabolites remain to be discovered. Because, as mentioned above, over $90 \%$ of genes or gene clusters for secondary metabolite biosynthesis have gone unnoticed. If we could activate these phenotypically silent genes or gene clusters for secondary metabolite biosynthesis, it may be possible to discover large numbers of new antibiotics more efficiently. Based on this notion, I began a study, which I call ASAP (Activation of Silent Antibiotics Productivity). The ASAP approach does not refer to a particular technique but to an idea for discovering new antibiotics as soon as possible. There will be various ways to activate silent antibiotics productivity, for example artificial control of the SARP-family transcriptional regulator genes. New approaches may free us from time-consuming and laborious classical approaches, such as improvement of culture conditions and obtaining mutant strains.

Ten years ago, genome sequencing was possible for only a few limited researchers due to the very high costs and requirement for large-scale facilities. However, both the lowering of the cost and the appearance of next-generation sequencers have enabled many researchers to perform genome sequencing. As a result, there has been an explosion in the number of genome sequences in literatures and databases. Although this was our awaited state, we are far from capable of obtaining out information efficiently or easily from genome sequences. We are still struggling in a sea of genome sequence data rather than swimming. The development of new technology to analyze genome sequences is a major priority so as to prevent drowning.

\section{ACKNOWLEDGMENTS}

It is my great honor to have received the Award of the Society of Actinomycetes Japan (2008). I would like to express my gratitude to those who recommended me, the nominating committee and the board members of the society. I am most grateful to Dr. Y. Koyama and Dr. K. Hotta for their continued guidance and encouragement. All of the works mentioned above could not be achieved without the following great people: Mr. M. Ichihara, Dr. S. Mizuno, Dr. Y. Uehara, Dr. K. Ishino, Dr. Y. Hoshino, Mrs. F. Saito, Dr. F. Kato, Dr. H. Ikeda, Dr. S. Omura, Dr. T. Shiba, Dr. Y. Sakaki, Dr. Y. Mikami, Dr. K. Yazawa, Dr. Y. Sasaki, Dr. K. Ueda, Dr. T. Beppu, Dr. Y. Ohnishi, Dr. S. Horinouchi, Dr. T. Dairi, Dr. S. Takahashi, Dr. H. Osada, Dr. A. Toyoda, Dr. Y. Takahashi, Dr. M. Hayakawa, Dr. N. Fujita, Dr. M. Hattori, Dr. A. Yamashita, Mr. K. Oshima, Dr. H. Hayashi, Dr. T. Kurata and all other collaborators and students. I would also like to express my appreciation to all people who used the FramePlot program. Finally, I would like to express my heartfelt thanks to my family.

\section{REFERENCES}

Agematu, H., Matsumoto, N., Fujii, Y., Kabumoto, H., Doi, S., Machida, K., Ishikawa, J. \& Arisawa, A. (2006). Hydroxylation of testosterone by bacterial cytochromes P450 using the Escherichia coli expression system. Biosci. Biotechnol. Biochem. 70, 307-311.

Bibb, M. J., Findlay, P. R. \& Johnson, M. W. (1984). The relationship between base composition and codon usage in bacterial genes and its use for the simple and reliable identification of protein-coding sequences. Gene 30, 157-166.

Chiba, K., Hoshino, Y., Ishino, K., Kogure, T., Mikami, Y., Uehara, Y. \& Ishikawa, J. (2007). Construction of a pair of practical Nocardia-Escherichia coli shuttle vectors. Jpn. J. Infect. Dis. 60, 45-47.

Drahl, Carmen. (2008). Antibiotic ideas: Studies advocate blocking cell-division protein, essential metabolic pathway. Chemical \& Engineering News 86, 15-15.

Hiratsuka, T., Furihata, K., Ishikawa, J., Yamashita, H., Itoh, N., Seto, H. \& Dairi, T. (2008). An alternative menaquinone biosynthetic pathway operating in microorganisms. Science 321, 1670-1673.

Hotta, K., Ishikawa, J., Ichihara, M., Naganawa, H. \& Mizuno, S. (1988). Mechanism of increased kanamycinresistance generated by protoplast regeneration of Streptomyces griseus. I. Cloning of a gene segment directing a high level of an aminoglycoside 3- $\mathrm{N}$-acetyltransferase activity. J. Antibiot. 41, 94-103.

Ikeda, H., Ishikawa, J., Hanamoto, A., Shinose, M., Kikuchi, H., Shiba, T., Sakaki, Y., Hattori, M. \& Omura, S. (2003). 
Complete genome sequence and comparative analysis of the industrial microorganism Streptomyces avermitilis. Nat. Biotechnol. 21, 526-531.

Ishikawa, J., Chiba, K., Kurita, H. \& Satoh, H. (2006). Contribution of rpoB2 RNA polymerase $\beta$ subunit gene to rifampin resistance in Nocardia species. Antimicrob. Agents Chemother. 50, 1342-1346.

Ishikawa, J. \& Hotta, K. (1991). Nucleotide sequence and transcriptional start point of the kan gene encoding an aminoglycoside 3- $N$-acetyltransferase from Streptomyces griseus SS1198PR. Gene 108, 127-132.

Ishikawa, J., Koyama, Y., Mizuno, S. \& Hotta, K. (1988). Mechanism of increased kanamycin-resistance generated by protoplast regeneration of Streptomyces griseus. II. Mutational alteration and gene amplification. J. Antibiot. 41, 104-112.

Ishikawa, J. \& Hotta, K. (1999). FramePlot: a new implementation of the Frame analysis for predicting protein-coding regions in bacterial DNA with a high $\mathrm{G}+\mathrm{C}$ content. FEMS Microbiol. Lett. 174, 251-253.

Ishikawa, J., Yamashita, A., Mikami, Y., Hoshino, Y., Kurita, H., Hotta, K., Shiba, T. \& Hattori, M. (2004). The complete genomic sequence of Nocardia farcinica IFM 10152. Proc. Natl. Acad. Sci. U.S.A. 101, 14925-14930.

Martins, M., Pluvinage, B., de la Sierra-Gallay, I. L., Barbault, F., Dairou, J., Dupret, J. M. \& Rodrigues-Lima, F. (2008). Functional and structural characterization of the arylamine $\mathrm{N}$ acetyltransferase from the opportunistic pathogen Nocardia farcinica. J. Mol. Biol. 383, 549-560.

Ohnishi, Y., Ishikawa, J., Hara, H., Suzuki, H., Ikenoya, M., Ikeda, H., Yamashita, A., Hattori, M. \& Horinouchi, S.
(2008). Genome sequence of the streptomycin-producing microorganism Streptomyces griseus IFO 13350. J. Bacteriol. 190, 4050-4060.

Omura, S., Ikeda, H., Ishikawa, J., Hanamoto, A., Takahashi, C., Shinose, M., Takahashi, Y., Horikawa, H., Nakazawa, H., Osonoe, T., Kikuchi, H., Shiba, T., Sakaki, Y. \& Hattori, M. (2001). Genome sequence of an industrial microorganism Streptomyces avermitilis: deducing the ability of producing secondary metabolites. Proc. Natl. Acad. Sci. U.S.A. 98, $12215-12220$.

Sasaki, N., Izawa, M., Watahiki, M., Ozawa, K., Yoneda, Y., Matsuura, S., Caminci, P., Muramatsu, M., Okazaki, Y. \& Hayashizaki, Y. (1998). Transcriptional sequencing: a method for DNA sequencing using RNA polymerase. Proc. Natl. Acad. Sci. U.S.A. 95, 3455-3460.

Sasaki, Y., Ishikawa, J., Yamashita, A., Oshima, K., Kenri, T., Furuya, K., Yoshino, C., Horino, A., Shiba, T., Sasaki, T. \& Hattori, M. (2002). The complete genomic sequence of Mycoplasma penetrans, an intracellular bacterial pathogen in humans. Nucl. Acids Res. 30, 5293-5300.

Ueda, K., Yamashita, A., Ishikawa, J., Shimada, M., Watsuji, T., Morimura, K., Ikeda, H., Hattori, M. \& Beppu, T. (2004). Genome sequence of Symbiobacterium thermophilum, an uncultivable bacterium that depends on microbial commensalism. Nucl. Acids Res. 32, 4937-4944.

Wietzorrek, A. \& Bibb, M. (1997). A novel family of proteins that regulates antibiotic production in streptomycetes appears to contain an OmpR-like DNA-binding fold. Mol. Microbiol. 25, $1181-1184$. 